\title{
POLITECNIA E INSTRUÇÃO PROFISSIONAL NA RÚSSIA REVOLUCIONÁRIA: O DEBATE PEDAGÓGICO DE PISTRAK E SHULGIN
}

\author{
POLITECNIA Y EDUCACIÓN PROFESIONAL EM RUSIA REVOLUCIONARIA: EL \\ DEBATE PEDAGÓGICO DE PISTRAK Y SHULGIN
}

\section{POLITECNIA AND PROFESSIONAL EDUCATION IN REVOLUTIONARY RUSSIA: THE PEDAGOGICAL DEBATE OF PISTRAK AND SHULGIN}

DOI: http://dx.doi.org/10.9771/gmed.v11i2.29676

\section{Iziane Silvestre Nobre ${ }^{1}$}

Resumo: Discorre-se sobre a educação politécnica, tratando das concepções de Pistrak e Shulgin, nas formulações sobre a politecnia e instrução profissional na Rússia revolucionária, percebendo que, quando se trata dos limites da educação soviética, um dos problemas esteve relacionado às questões socioeconômicas e a educação técnica dissociada da formação da consciência revolucionária.

Palavras-chave: Politecnia. Instrução profissional. Educação soviética.

Resumen: Se discute sobre la educación politécnica, tratando las concepciones de Pistrak y Shulgin, en las formulaciones sobre la politecnia e instrucción profesional en la Rusia revolucionaria, percibiendo que, cuando se trata de los límites de la educación soviética, uno de los problemas estuvo relacionado a las cuestiones socioeconómicas y la educación técnica disociada de la formación de la conciencia revolucionaria.

Palabras clave: politécnico; educación profesional; educación soviética; nueva política económica

Abstratc: It deals with polytechnic education, dealing with the conceptions of Pistrak and Shulgin, in the formulations on polytechnics and professional education in revolutionary Russia, realizing that when it comes to the limits of Soviet education, one of the problems was related to socioeconomic issues and technical education dissociated from the formation of the revolutionary consciousness.

keywords: polytechnic; vocational education; Soviet education

\section{Introdução}

Este artigo tem a proposta de realizar uma discussão conceitual do que sejam instrução profissional, politecnia e omnilateralidade, tendo como base as considerações de autores marxistas que versaram acerca dessa temática, situando o conceito de politecnia nos debates dos educadores soviéticos, especialmente as concepções de Pistrak e Shulgin.

Embora haja semelhanças na proposta pedagógica desses dois autores soviéticos, as diferenças aparecem porque para o primeiro, a politecnia corresponde ao domínio técnico da atividade e como uma possibilidade de articulação entre campo e cidade, possuindo o objetivo de implantar técnicas para um processo de industrialização do campo e diminuir o fosso cultural entre cidade e campo. Para Shulgin, a politecnia aparece como um sistema mais ampliado de educação, no qual está articulado o trabalho político- 
social ao trabalho produtivo na formação da consciência revolucionária, havendo modificações na aplicabilidade da metodologia dos complexos e na utilização dos termos que consideram o trabalho políticosocial da escola, sendo para o primeiro denominado de trabalhos improdutivos e para o segundo de trabalho socialmente necessário.

Essa diferenciação existente é importante a fim de pontuarmos que o termo "trabalho socialmente necessário", embora nele não esteja dito diretamente como práxis, mas a práxis refere-se aos trabalhos político-sociais realizados junto a comunidade que a escola está inserida. Esse termo aparece para elucidar que tais trabalhos também são necessários no processo de formação da consciência revolucionária

Portanto, pensar em uma educação que abarque a integralidade do ser na sociedade capitalista a partir da relação entre trabalho, ensino e práxis na teia das contradições da sociedade capitalista, não sendo apresentada, todavia, como a proposta que responde pelo processo formativo revolucionário da classe trabalhadora, mas como aquela que fomenta o debate progressista revolucionário, possibilitando a formação do sujeito revolucionário no interior da sociedade de classe. Nesse sentido, as experiências históricas de educação revolucionária nos ajuda a pensar numa educação que dialogue e procure superar as contradições do sistema capitalista no limiar entre o velho e o novo mundo.

Desta forma, contextualizaremos um debate realizado entre Nosella (2007) e Sousa Junior (2009), no qual o segundo aponta dois conceitos de politecnia presente na obra de Marx, diferente do termo “educação tecnológica”. Posteriormente, faremos a discussão centrada no debate dos educadores soviéticos a partir de duas obras principais: "Rumo ao politecnismo" e "Ensaios sobre a escola politécnica". Por conseguinte, contextualizaremos com as politicas educacionais da época a fim de compreendermos a mudança que se deu de uma forma de educação politécnica para outra que mais se parece como uma instrução meramente profissional.

Em tempos que a educação para a classe trabalhadora segue uma tendência de torna-la mais tecnicista e pluriprofissional, cabe recorrermos aos conceitos vigentes a fim de iluminar nossa prática na defesa de uma educação que atenda as necessidades da classe trabalhadora.

\section{O conceito de politecnia: contextualizando o debate}

Há uma polêmica, dentro dos escritos marxistas, do que seja uma educação politécnica e uma educação tecnológica, como a bandeira progressista defendida por Marx no campo da educação. Não pretendo, nesse artigo, dissertar acerca dessa polêmica, porém, gostaria apenas de situar o leitor na discussão impetrada por Nosella (2007); Saviani (2007) e Sousa Junior (2009).

Seguindo a direção teórica de Sousa Junior (2009), nos escritos marxistas sobre educação, Marx defende duas propostas de politecnia: uma em que é funcional ao sistema capitalista e outra considerada como progressista, por julgar que na proposta dessa segunda deve conter o princípio da união trabalho e ensino associado aos exercícios físicos, lembrando que, ambas as propostas podem ser realizáveis na esfera do sistema capitalista, no entanto, a segunda, procura atender minimamente aos interesses do proletariado ao conceder-lhes uma educação que une as atividades do pensar ao fazer integrados às atividades físicas. 
Segundo Sousa Junior (2009), há uma ambiguidade conceitual nos termos de politecnia e omnilateralidade, sendo que este último é confundido com o termo de educação tecnológica. Parte dessa ambiguidade é justificado porque, as primeiras traduções das contribuições de Marx para a educação é retirado da obra de Manacorda que, segundo o autor, considera educação politécnica como uma formação pluriprofissional e concede à educação tecnológica como àquela que responde a articulação entre teoria e prática, ajudando assim, a formar o homem omnilateral.

Partindo dessas elaborações, Nosella (2007) enfrenta a polêmica acerca do conceito de politecnia e educação tecnológica, alegando o equívoco da defesa dos educadores marxistas pela educação politécnica, uma vez que ela diz respeito a esta formação pluriprofissional, sendo então mais adequado realizar a defesa da educação tecnológica, devido à articulação entre teoria e prática contida na proposta.

Partindo desse pressuposto, Sousa Junior (2009) constrói sua argumentação baseada na negação da de Nosella, concluindo que, na contemporaneidade, a compreensão de educação tecnológica apresenta algumas distorções, além de que, segundo o autor, há um equívoco na concepção esboçada por formação omnilateral, tendo em vista que, nos moldes em que está posto, parece que basta atingir um elevado nível cultural na sociabilidade burguesa para que acessarmos uma formação omnilateral.

O autor salienta que por mais progressista que seja a proposta da politecnia, a formação humana em seu sentido pleno não poderá ser alcançada por causa dos limites estabelecidos pelo capital. A proposta de união trabalho e ensino pode até estar inserida nos programas escolares das escolas burguesas, porém sua efetivação não se coaduna numa sociedade marcada pela opressão entre as classes.

A educação tecnológica, exposto por Manacorda (2000) como a articulação entre teoria e prática, capaz de elevar o nível cultural dos trabalhadores, possibilitando o desenvolvimento da plena manifestação das suas individualidades artísticas, científicas e culturais (SOUSA JR, 2009), muito se parece com o conceito de omnilateralidade. No entanto, é necessário salientar que dentro dos limites estabelecidos pelo capital, a plena e total manifestação de si mesmo não poderá ocorrer sob o signo de relações estranhadas.

Em outro texto, o autor citado distingue as duas concepções referentes à politecnia e omnilateralidade, salientando que:

Os dois conceitos guardam em si uma distinção fundamental: O primeiro, referente à formação politécnica, traz consigo uma limitação, pois comporta apenas uma série de habilidades manipuladoras e conhecimentos técnicos úteis para a produção social; o segundo, referente à formação onilateral, representa uma formação ampla do homem nas suas múltiplas possibilidades, enquanto ser livre que só se constrói em relações sociais livres; enquanto a politecnia se mostra uma proposta de educação/formação articulada às possibilidades dialéticas da contradição do trabalho abstrato, a onilateralidade precisa articular-se a todo o conjunto das atividades humanas, portanto, às dimensões do trabalho e da práxis social livres e da sociabilidade não alienada/estranhada. (SOUSA JR, 2010, p. 74)

A união trabalho e ensino é um dos princípios marxianos da educação, embora não represente em sua totalidade sua concepção de educação. Nessa esteira, Sousa Jr (2010) esclarece que as duas propostas podem ser efetivadas ainda no reino da necessidade, embora a proposta marxiana não seja plenamente realizável devido aos limites estruturantes da sociabilidade burguesa, porém uma representa a proposta burguesa de educação e a outra representa os interesses e as concepções proletárias. A educação politécnica 
na proposta de educação burguesa refere-se a mero treinamento polivalente, enquanto que a preocupação com a formação humana afastada da determinação imediata do capital só se encontra na proposta de educação politécnica marxiana.

No entanto, como já afirmamos antes, não existe um consenso em torno do conceito de politecnia entre os educadores marxistas. A proposta marxiana de educação politécnica abrange uma concepção sobre os elementos componentes de um processo de formação, podendo ser disputada dentro da sociedade burguesa, adquirindo um caráter de proposta política, além de envolver e pressupor uma concepção geral sobre formação proletária durante o reino da necessidade. Todavia, é necessário reconhecer que o Estado burguês não possui interesse em oferecer esse tipo de educação que contemple os interesses dos trabalhadores, por essa razão, concordamos que o momento no qual a proposta da politecnia melhor se adequa é na sociedade em transição.

Marx elabora sua proposta de educação politécnica fundada na realidade, compreendendo a indispensabilidade dos trabalhadores se apropriarem dos conhecimentos dominantes por uma necessidade concreta de sobrevivência. Nesse sentido, a educação em Marx está fincada na realidade, objetivando alterar as relações de dominação da sociedade, cabendo, portanto, o esclarecimento de que não é a educação politécnica a responsável pela libertação do homem, mas um conjunto de fatores articulados: trabalho, práxis político-educativa e instrução escolar, voltados para uma perspectiva de emancipação social.

As divergências em torno dos conceitos de educação politécnica, educação tecnológica e educação omnilateral são muitas. Nosella (2007), por exemplo, atribui que essa "confusão ideológica" acerca dessas propostas se justifica pela tradução do termo, pois em algumas traduções aparece o termo "educação politécnica" e em outros "educação tecnológica" como germe da educação do futuro. Embora, o autor citado justifique que sua crítica a politecnia, como bandeira de luta dos educadores marxistas, não é apenas de ordem semântica, grosso modo, pela exposição do texto, seus argumentos se constroem dessa maneira, reforçando mais o caráter semântico do que mesmo o caráter teórico das distinções dos termos. Nosella direciona uma crítica aos educadores marxistas por não enfrentarem a questão semântica, ressaltando que o único que se propõe a realizar um debate sobre isso é o Saviani (2007), que, por sua vez, reforça a posição de que a semântica do termo não retira o caráter que Marx dava a educação politécnica. Porém, ao mesmo tempo em que o autor demarca sua posição, demonstra uma flexibilidade na aceitação de qualquer uma das terminologias, deixando a entender que pouco importa o conceito e a ideologia subjacente ao termo. Saviani até expõe que o termo "tecnologia" foi apropriado pela concepção dominante e que o termo politecnia foi preservado na tradição marxista, porém, a condução do seu debate parece confluir de que a distinção do termo faz pouca diferença nos debates marxistas sobre educação.

No tocante à preservação do termo "politecnia" na tradição marxista, Nosella (2007) afirma que o termo "ensino politécnico" foi usado por Lênin e não por Marx. O autor critica as políticas educacionais russas por serem inspiradas no iluminismo/positivismo, por terem privilegiado a formação na indústria nascente, apesar de reconhecer que as escolas politécnicas da União Soviética eram as melhores que funcionavam. Quando ele questiona por que o termo permaneceu mesmo após a morte de Lênin, responde, fundamentado em Manacorda, que os textos de Marx e Engels foram traduzidos incorretamente para o 
idioma russo, permanecendo nas políticas educacionais socialistas porque assim Lênin determinou. Tal explicação, contudo, não parece suficiente. É até aceitável que os textos tenham sido traduzidos de maneira incorreta, mas daí supor que permaneceu por conta da autoridade de Lênin, não faz muito sentido. Não conseguimos visualizar um interesse concreto de Lênin na manutenção do termo politecnia.

A influência de Lênin nas políticas educacionais russas se deu até 1921, morreu em 1924. Após esse ano, houve outras reformas educacionais as quais se distanciaram em grande medida do que vinha sendo construído. Lênin não assinou nenhum decreto obrigando a utilização do termo mesmo após a sua morte. Portanto, é mais fácil conjecturar que a manutenção do termo se deu devido à tradução incorreta e perdurou porque esse nome se destacou no linguajar dos falantes, passando a adquirir outro sentido nas relações sociais.

A resistência de Nosella (2007) em aceitar o termo politecnia fundamenta-se no pressuposto de que ela é a "proposta predileta da burguesia, porque é uma forma de instrução destinada a fornecer à indústria uma força de trabalho capaz de ter versatilidade pluriprofissional, adaptável a várias profissões" (p. 145), argumentando ainda que:

O "politecnismo" sublinha tema da disponibilidade para vários trabalhos ou para as variações dos trabalhos, enquanto a "tecnologia" sublinha, com sua unidade de teoria e prática, o caráter de totalidade ou omnilateralidade do homem. [...] O primeiro destaca a ideia de multiplicidade da atividade [...], o segundo, a possibilidade de uma plena e total manifestação de si mesmo, independente das ocupações específicas das pessoas. (ibidem, p. 145)

Partindo dessa perspectiva, o autor citado defende veementemente que: "embora nos textos de Marx as expressões 'politecnia' e 'tecnologia' se intercalem, só a expressão 'tecnologia' evidencia o germe do futuro, enquanto 'politecnia' reflete a tradição cultural anterior a Marx" (NOSELLA, 2007. p.145).

Ademais, para além da polêmica levantada por Nosella (2007), nossa fundamentação teórica, apoiada em Sousa Jr (2010), consiste na diferenciação entre os dois conceitos de educação politécnica. Mesmo na perspectiva marxiana, a educação politécnica apresenta seus limites por estar circunscrita a um determinado contexto social.

Sousa Jr (2010, p. 84) destaca que

A politecnia, assim se define por não precisar romper com o sistema do capital; por não precisar se basear no conjunto das relações sociais novas, transformadas; por consistir de um conteúdo limitado - por mais progressista que seja; por se articular às dimensões do trabalho abstrato; e por estar vinculada às questões específicas dos processos produtivos (momento laborativo).

Por sua vez, Manacorda (2000) se apoia em alguns trechos d'O capital e nos Grundisses, para afirmar que

Marx fala da tecnologia teórica e prática, com o objetivo de formar um homem omnilateral, isto é, não só capaz de lidar com as transformações advindas dos desenvolvimentos tecnológicos da indústria, mas também em condição de desenvolver todas as possibilidades culturais pessoais, de estudo e também de diversão, de jogos, de participação na vida social. (MANACORDA apud SOARES, 2004, p. 4)

Sousa Jr (2009) discorda dessa afirmação argumentando que o conceito, tal como foi exposto, se refere apenas ao cidadão burguês que trabalhe e tenha acesso à cultura. $\mathrm{O}$ limite dessa conceituação de 
omnilateralidade se encontra no próprio limite da sociabilidade burguesa em promover essas possibilidades de desenvolvimento integral para todos. O autor expõe que:

\begin{abstract}
Identificar no termo 'tecnológico' "a unidade de teoria e prática, o caráter de totalidade ou omnilateralidade do homem" parece um inteiro despropósito. Ora, em Marx a tecnologia, até que se dê a superação da alienação, é produto do trabalho abstrato, do trabalho alienado, é um tipo de expressão das relações sociais estranhadas, assim como representa apropriação capitalista (material e espiritual) dos produtos do trabalho. A tecnologia é justamente uma das formas através das quais se manifesta a separação capital e trabalho, a divisão entre trabalho intelectual e trabalho manual e a alienação. Por sua vez, a formação onilateral de maneira alguma poderá ser pensada senão como momento da superação da alienação, o que o ensino tecnológico, por sua vez, não alcança. (SOUSA JR, 2009, p. 10)
\end{abstract}

Compreendemos que a questão semântica do termo na contemporaneidade finda por representar uma posição política no campo da esquerda. Embora tenhamos consciência de que uma política educacional considerada progressista não seja capaz de alterar as relações de dominação na sociedade, desprezar a educação como um espaço de disputa, e como tal, a bandeira da politecnia como proposta de luta da esquerda, contribui para fomentar um debate acerca da educação que serve aos interesses da classe trabalhadora, tendo como horizonte a materialidade do real, mesmo reconhecendo que uma educação que sirva aos interesses proletários não é interessante ao Estado burguês.

A defesa da politecnia está fundamentada na concepção de que através dela se busca dominar “os fundamentos científicos, teóricos e práticos dos diversos processos de trabalho. Esse domínio, por sua vez, deve atuar contra a alienação da atividade do trabalho, muito embora por si só não a supere" (SOUSA JR, 2010, p. 82). O domínio científico é importante, porém, concordamos que ele por si só seja insuficiente para a formação da classe trabalhadora numa perspectiva revolucionária, necessitando, pois, acionar os outros elementos que associam teoria e prática revolucionária, na organização da classe trabalhadora visando alterar o status quo.

Nosella (2007) reivindica ainda a ausência de uma educação com sentido humanista nas discussões dos educadores marxistas. No entanto, é preciso reiterar que essa concepção está presente na conceituação de omnilateralidade, referente a uma formação no sentido mais amplo, capaz de favorecer a plena manifestação do homem, cabendo salientar que isso só será possível após a supressão dos antagonismos de classes, tendo em vista que a educação não será ofertada/reproduzida de acordo com a divisão social do trabalho.

Sousa Jr (2010, p. 84) conceitua omnilateralidade como

a uma formação humana de caráter mais amplo, que depende da ruptura com a sociabilidade burguesa, com a correspondente divisão social do trabalho, com as relações de alienação e estranhamento, com o fetichismo, com o antagonismo de classes. A formação onilateral não se restringe ao mundo do trabalho abstrato ou das instituições formais de educação - por mais progressistas que sejam. A formação onilateral depende, decisivamente das mediações que se realizam na totalidade do intercambio social não estranhado.

A partir dessa conceituação, não se pode confundir o conceito de educação omnilateral com o de educação tecnológica. Deste modo, ratificamos que a educação omnilateral não pode coincidir num tipo de sociedade marcada por relações sociais estranhadas e alienadas. Entendemos, por conseguinte, que a 
existência de uma formação humana em seu sentido pleno só pode ser encontrada na omnilateralidade com a manifestação nos mais diferentes aspectos do homem, considerando que

A omnilateralidade em Marx é um tipo de formação que representa um amplo desenvolvimento das mais diferentes possibilidades humanas, como um todo, nos planos da ética, das artes, da técnica, da moral, da política, da ciência, do espírito prático, das relações intersubjetivas, da afetividade, da individualidade, etc. (SOUSA JR, 2010, p. 15)

Diante disso, o homem omnilateral não pode ser formado no seio de uma sociedade estranhada. Por essa razão, ao defendermos um programa marxiano ligado não apenas ao princípio da união trabalho e ensino, mas interligado com outros aspectos da vida social, estamos enfatizando a importância da práxis e seu princípio educativo imanente.

Nosella (2007) e Sousa Jr (2009) embora partam de perspectivas diferentes em muitos aspectos, concordam que houve um reducionismo nas formulações marxistas para a educação. Enquanto o primeiro se apoia na proposta de educação unitária, o segundo aponta para a necessidade de articular as várias dimensões da práxis como um amplo processo formador.

Nessa perspectiva, o programa de educação em Marx é bem mais completo, uma vez que se relaciona com a necessidade de formação da classe trabalhadora na apreensão dos códigos dominantes, numa formação crítica, política e emancipatória, realizada nas trincheiras da luta social a fim de superar o caráter reprodutivista da escola formal e culmina numa proposta de educação integral, livre das amarras do capitalismo.

Concordamos com Sousa Jr (2010 p. 31) quando diz que "o homem novo e a nova consciência são interdependentes e ambos se constroem no processo educativo da práxis revolucionária". Partindo disto, não se pode conceber a conquista do poder para que depois se efetive um tipo de educação transformadora. A educação, com vistas à transformação social, se dá ainda nas contradições do capitalismo e o homem novo e a nova consciência são formadas num processo dialético, dinâmico, concomitante ao processo de emancipação humana.

\section{A educação politécnica na transição revolucionária}

Shulgin (2013) utiliza uma terminologia designada por pedagogia do meio, como aquela educação que atua nas contradições da sociedade. $\mathrm{O}$ autor, embora não tenha utilizado a palavra práxis em sua proposta formativa, nos deixa explícito que o sistema politécnico sugerido por ele reporta-se a uma educação que integra trabalho, práxis e ensino numa perspectiva revolucionária.

$\mathrm{Na}$ visão de Shulgin (2013), a proposta politécnica corresponde a uma espécie de modelo de educação da sociedade comunista, por permitir que os jovens se familiarizem com todo o sistema de produção, permitindo-os que passem de um ramo a outro dependendo das necessidades da sociedade ou de suas próprias inclinações, libertando-os da unilateralidade. Porém, ela por si só é insuficiente, tendo em vista que a unilateralidade do homem não pode estar concentrada apenas no campo das ocupações.

Shulgin (2013, p. 84) reforça suas concepções com a crença de que "uma sociedade organizada sob os moldes comunistas permitirá aos seus membros utilizar, sob todos os aspectos, as suas capacidades 
desenvolvidas de modo multilateral". As habilidades aprendidas pelo homem no período da transição, enquanto subsistir o reino da necessidade, não são capazes de substituir a educação omnilateral, mas já se constituem em passos importantes e necessários rumo à educação omnilateral.

A politecnia, para Shulgin (2013), é uma preparação para a educação omnilateral, tendo em vista que o sistema politécnico para ele, esta relacionada não apenas a uma formação pluriprofissional, mas já se constituem numa preparação importante, tendo em vista que articula os aspectos teóricos-práticos da formação, carregada do conteúdo político. Podemos supor que, nesse formato, a educação politécnica se articula à práxis, uma vez que a formação politécnica se refere à formação para os trabalhos produtivos e para os trabalhos socialmente necessários.

Para o autor, as divisões entre cidade e campo tendem a desaparecer à medida que as diferenças de classes são eliminadas. O fim das classes sociais garante, por sua vez, que as mesmas pessoas que realizem trabalhos na indústria, saibam fazer na agricultura, apresentando uma tendência do trabalhador unilateral desaparecer consoante ao fim dos antagonismos, devendo ser construído, para o autor, de forma simultânea no campo e na cidade.

A confluência entre o pensamento de Shulgin com os de Krupskaia e Pistrak aparece na articulação dos trabalhos da fábrica mais a aprendizagem das técnicas agrícolas, porém, os dois educadores não colocavam abertamente a tendência do desaparecimento entre cidade e campo. Andrade (2011) sublinha que nos textos de Krupskaia aparece a articulação das escolas do campo com as escolas da cidade, através da Escola de Verão, como forma de diminuir a distância entre campo e cidade. A alternância articulada das aulas com os trabalhos artesanais e nas cooperativas agrícolas, cujo custo da instrução seria acordado com os operários, complementados por alunos, professores e funcionários, deveria suprir a necessidade dos moradores do campo ao acesso à cultura.

Para Pistrak, conforme salienta Freitas (2013, p. 9),

a distinção entre cidade e campo é uma das peculiaridades a serem consideradas na criação prática da escola politécnica, e a produção agrícola constitui-se em um amplo e específico complexo tecnológico, podendo ser o ponto de partida da inserção nos processos produtivos nas escolas do campo.

Por outro lado, o conceito de instrução profissional, segundo Dore (2013), estava relacionado ao processo de produção artesanal. O profissional formado nesse formato era apenas um especialista que sabia dominar apenas uma técnica e/ou função de todo o processo produtivo. Andrade (2011) destaca que instrução profissional para Krupskaia se referia ao domínio da técnica e dos meios de produção. Deste modo, podemos supor que este formato de educação apenas contribui para formar profissionais unilaterais, possuindo ainda um agravante concernente ao aprofundamento da divisão social do trabalho. A divisão entre trabalho manual e intelectual continuaria a separar as atividades do homem que pensa das do homem que executa, permanecendo a opressão do homem sobre o homem, tendo em vista a permanência de uma hierarquia dentro do processo produtivo.

Dentre as principais dificuldades do contexto histórico: fome, guerra, epidemias, ausência de um referencial teórico em educação revolucionária e por ser a primeira experiência de tentativa de implantação 
do socialismo, os problemas práticos se colocaram devido também à extensão do território russo. A falta do elo entre cidade e campo demonstrava uma completa desarticulação entre cidade e campo. Nelas, o trabalho produtivo não estava associado ao trabalho socialmente útil; havia uma distância entre os trabalhos do campo e os trabalhos da cidade e os métodos adotados por Pistrak não estavam coadunados aos trabalhos da fábrica.

Nessa direção, a escola não conseguiu se constituir como o centro cultural na vida dos estudantes e, por conta dessa fragilidade, ainda subsiste uma lacuna ideológica entre os professores e os filhos dos trabalhadores. Os alunos, mesmo depois de alguns anos, ainda não tinham compreendido as maiores conquistas da revolução, dificultando a criação de alguns laços de companheirismo e cumplicidade entre eles (LILGE, 1988).

Desta maneira, com as mudanças impetradas pela Nova Política Econômica, a politecnia cedeu lugar para o ensino profissional, a formação, destaca Shulgin (2013), deixou de ser no trabalho e se transformou para o trabalho, resultando apenas no desenvolvimento de habilidades. $\mathrm{O}$ autor destaca que a aprendizagem das habilidades é necessária, mas elas não são um objetivo em si mesmo. A aprendizagem das habilidades com ideias vazias abriga a contrarrevolução, por vezes a ideologia. Deste modo, a politecnia, como propulsora da formação do homem multilateral havia regredido, o que levou acusação de Shulgin (2013) de que a escola tinha voltado a ser verbalista e escolástica. O autor observa que poucas crianças de nove anos chegavam a concluir o curso, relatando que ainda existia uma lacuna ideológica muito grande entre os professores e os filhos dos trabalhadores.

Pistrak e Shulgin partem do mesmo ponto de vista e do mesmo referencial teórico quando percebem a desarticulação entre teoria e prática. De um lado, Pistrak acreditava que o Estado deveria extinguir-se somente depois que a classe trabalhadora firmasse seu poder como classe revolucionária (FREITAS, 2009); de outro, Shulgin esperava que o Estado e todos os seus aparelhos ideológicos fossem destruídos logo após a revolução. Se de um lado, de acordo com Freitas (2009), Pistrak avaliava que a prática tinha se sobreposto à teoria; houve também uma debilitação na prática à medida que o politecnismo não conseguiu superar a divisão entre trabalho manual e intelectual, nem tampouco realizou a superação das relações alienadas e estranhadas.

A politecnia para Shulgin correspondia à diminuição da distância entre trabalho manual e intelectual, entre o homem do campo e o homem citadino. O educador ressalta que a escola politécnica nasce na sociedade burguesa, mas é no período da transição que ela se desenvolve a serviço da classe trabalhadora, surgindo a possibilidade de o homem se desenvolver plenamente. Shulgin sugere que a politecnia, nos moldes aqui expostos, é uma espécie de etapa para o que compreendemos em Marx como educação onilateral. O entendimento de politecnia do educador é ampliado na medida em que suplanta a dimensão pedagógica do trabalho com as diversas esferas da vida do ser social, articulando teoria e prática numa relação dialética e contínua. As críticas do autor à educação politécnica de Pistrak dizem respeito à redução do ensino politécnico, ao aprendizado de técnicas referentes ao artesanato múltiplo. Dessa forma, reduzia as possibilidades do politecnismo no período da transição. Tal concepção, na visão de Shulgin (2013), impedia uma relação orgânica do programa escolar com o trabalho, contribuindo sobremaneira para 
a ampliação da distância do campo e da cidade.

O autor destaca que essa concepção de politecnia se distancia da proposta elaborada por Marx e Engels. Para ele,

\begin{abstract}
De fato, enquanto Marx e Engels falam em relação à escola politécnica, eles mencionaram aquela etapa do desenvolvimento da sociedade humana em que não haverá cidade e campo com suas relações, quando será fácil passar os meninos de um trabalho para outro - hoje seria o trabalho agrícola, amanhã a produção na fábrica, no dia seguinte o trabalho puramente teórico etc. E temos nós esta oportunidade? Não! Temos cidade e campo, é evidente, e isso permite uma vasta área de trabalho: para as crianças do campo na fábrica, para as urbanas, na agricultura. Sim, e o próprio trabalho no campo é também primitivo. E na cidade? Será que podemos passar todos os meninos pela fábrica para ensiná-los? Então a monotonia da vida rural sente a desconexão da vida mundial; isso não pode ser ignorado, mas o nosso programa naturalmente, introduz as crianças nas relações de trabalho (SHULGIN, 2013 p. 106)
\end{abstract}

Para Shulgin (2013), o politecnismo é um sistema inteiro de reeducação das massas. A politecnia nasce no interior da fábrica, no interior da sociabilidade burguesa, mas é no período da transição que ela se desenvolve plenamente. $\mathrm{O}$ autor acreditava que trabalhando as diversas possibilidades advindas do politecnismo, isso seria um indicador de extinção do fosso de distância entre cidade e campo, se constituindo num dos primeiros a defender a pedagogia do campo. $\mathrm{O}$ autor defendia que a necessidade de formar especialistas não impedia a ampliação da cultura geral para todos os trabalhadores. Dessa forma, a educação politécnica não prejudicava a necessidade da produção.

Contudo, o que podemos observar como entraves ao pleno desenvolvimento da educação, Nesse formato, foram às inúmeras dificuldades materiais, a falta de recursos econômicos, tecnológicos, de pessoal, apto a atender às enormes demandas da população, a resistência e boicote de parte dos profissionais, entre outros. As privações impostas pelo contexto socioeconômico sufocaram as possibilidades educativas emancipatórias, notadas principalmente após a implantação da Nova Política Econômica - NEP. A aceleração do desenvolvimento econômico e seu regresso para uma forma de capitalismo de Estado (OYAMA, 2010) fizeram com que a educação para o desenvolvimento de uma consciência socialista sucumbisse, passando a atuar prioritariamente na formação de quadros para a ocupação de postos nas fábricas e empresas.

A implantação da NEP ocasionou, dentre outras coisas, a inserção precoce das crianças no trabalho produtivo, a redução da formação geral em dois anos e a substituição da escola politécnica pela escola monotécnica. Os autores Lilge (1988), Dore (2013) e Oyama (2010) dissertam na mesma direção, salientando que Lênin lamentou esse recuo, porém considerou necessário tendo em vista que "sem o aumento da produção, a revolução não venceria” (FERREIRA JR \& BITTAR, 2011, p. 383). Lilge (1988 p. 6) ressalta que durante a última parte da Nova Política Econômica, a educação politécnica teve poucos avanços, "poucos estudantes se engajavam no trabalho manual." A partir do predomínio da instrução profissional em detrimento da instrução politécnica, Shulgin, segundo Lilge (1988), acusa que as escolas soviéticas regrediram ao verbalismo e ao escolasticismo, persistindo uma lacuna ideológica entre os professores e os filhos da classe trabalhadora.

É importante pontuar que, dentro daquele contexto histórico da NEP, o maior agravante se deu 
na acentuação da formação para o trabalho em detrimento da formação da consciência revolucionária, articuladas com as diversas práxis sociais. À medida que ocorreu um recuo na proposta formativa, percebemos que a resistência ideológica se acentua, abrindo espaços para fomentar as mais diversas ideologias, especialmente as conservadoras.

A formação para o trabalho, por si só, é incapaz de promover os laços revolucionários e a formação dos laços revolucionários, necessitando, por isso, da articulação da práxis combinada com a instrução e a formação pelo trabalho, nos mais diversos espaços organizativos da classe trabalhadora.

Deste modo, podemos constatar que a educação politécnica esboçada por Marx, tratando-se de uma educação que alia união trabalho e ensino mais às atividades físicas, políticas, sociais e culturais, existiram nos primeiros anos. Nos relatos realizados por Pistrak, percebemos que a perspectiva do homem novo forjado no seio das contradições estava bem postos por meio do método utilizado pela escola do trabalho. Posteriormente, as sucessivas reformas educacionais altera substancialmente a concepção de educação politécnica, havendo, por conseguinte, a substituição do sistema politécnico para o sistema de instrução profissional.

\section{A "politecnia" na formação dos quadros especialistas}

A politecnia tomada como uma proposta pedagógica ampliada, que atua nas contradições no ainda reino da necessidade se dilui quando o aspecto político se perde no processo da burocratização da práxis. A burocratização da práxis recrudesce também à práxis produtiva, no sentido de que, ao focar na formação para o trabalho, os aspectos não mensuráveis da formação pedagógica estão marcados pela dimensão de uma educação tecnicista.

Pistrak (2015) em seu livro "Ensaio sobre a escola politécnica" deixa claro que a prioridade adotada pelos educadores soviéticos foi à formação para o trabalho, demonstrando que esta formação para o trabalho deu-se sobre as mesmas bases da educação tecnicista capitalista, devido à introdução do taylorismo nos processos escolares, diminuição da grade teórica do curso e a supressão da práxis políticapedagógica. É verdade que o contexto socioeconômico reivindicava uma educação voltada para o aumento da produção, no entanto, a formação pela práxis política-pedagógica ajuda a formar o novo homem dentro ainda das contradições do velho.

Nesse livro, Pistrak (2015) justifica as mudanças da proposta de educação politécnica, enumerando as diferenças socioeconômicas de um local para o outro, referenciando-se, para isso, na justificativa de Lenin para a implantação da NEP, falando das diversas formações socioeconômicas existentes na Rússia. O autor apresenta um trecho do programa escolar do partido e o discurso de Marx no Congresso de Genebra para justificar as possíveis retaliações que eles poderiam ter. Dentro do programa escolar do partido pontua a proposta de ligar o trabalho socialmente produtivo com o ensino livre da influência religiosa e, por outro lado, a citação do Marx aparece a fim de justificar a diminuição da idade das crianças nos processos produtivos para nove anos, dividindo as crianças e os adolescentes em três grupos: o primeiro, crianças entre nove e dez anos; o segundo, adolescentes entre treze e quinze anos, enquanto o 
terceiro, eram para moças e rapazes entre dezesseis e dezessete anos, sugerindo que o trabalho do primeiro grupo, seja realizado em casa ou nas oficinas com limitação de tempo de quatro horas, enquanto o terceiro grupo, devesse ser estabelecido pelo menos uma hora para comer e descansar.

Entendemos que, de certo modo, Pistrak (2015) estava preocupado em justificar os possíveis recuos da educação soviética, apontando porque eles estavam elegendo a categoria trabalho como central no programa escolar e porque havia diminuído a idade de ingresso das crianças no trabalho e aumentando as horas destinadas ao trabalho fabril.

$\mathrm{Na}$ verdade, o que Pistrak (2015) estava querendo dizer era que a educação soviética estava atendendo a uma reivindicação econômica, uma vez que Stalin havia estabelecido os planos quinquenais, além de que, a demanda da formação escolar exigia a formação de quadros especialistas para atuar nas fábricas.

Em outro momento do texto, Pistrak (2015 pag. 50) apontará as principais diferenças entre as escolas do campo e as escolas da cidade, uma vez que os processos produtivos no campo exigirão tecnologias específicas, pontuando que:

A escola do campo deve ser construída de modo a acelerar o processo de industrialização do campo e, consequentemente, alterar o método de gestão existente, apoiar o processo de introdução de tratores, de máquinas, de produtos químicos e da eletrificação do campo, para conduzir a economia camponesa pelo caminho da cooperação e da coletivização, travando com isso uma luta ativa contra os elementos capitalistas no campo e desalojando-os para fora de sua economia.

Os esforços dos educadores soviéticos, no que diz respeito à educação no campo, era alavancar o desenvolvimento das forças produtivas, no entanto, ao utilizar os métodos burgueses para alcançar o objetivo de fortalecer a educação do campo, enfraqueceu a luta de classes, uma vez que a ênfase da educação soviética passou a ter como prioridade absoluta, a formação para o trabalho.

Admitimos que seria uma espécie de idealismo, considerando todas as problemáticas impostas pelo contexto soviético, apostar na via de um culturalismo, desconsiderando a necessidade de formar quadros para atuar nas fábricas, além de que, não se constitui em nenhum "pecado" se apropriar de alguma metodologia burguesa e emprega-la para os fins da revolução. O pecado aparece quando a formação para o trabalho é fragmentada, quando os processos produtivos não ligam os elementos teóricos da educação com o conhecimento dos processos de produção. Este pecado é reconhecido por Pistrak (2015) quando o autor salienta que as pontes entre teoria e prática ainda não estão formadas suficientemente.

Pistrak (2015) ainda se referencia em Ford para elucidar o ideal de formação a partir da comparação da planta da produção da tecnologia de veículos. O autor pontua a definição do modelo a ser produzido, para depois ser dividido em um grande número de peças separadas, construindo uma máquina especial para cada processo produtivo. Assim posto, fica parecendo que o estudante aprenderá as habilidades em apenas uma máquina, reforçando a fragmentação do ensino, ao possibilitar que o estudante se especialize em uma determinada máquina, acarretando em um desconhecimento dos conhecimentos gerais acerca do produto.

Para acabar de completar, a própria divisão das disciplinas, segundo Pistrak (2015), fortaleciam o 
conceito de educação tradicional, acarretando que a formação teórica não se misturava com a formação prática, prejudicando assim, a formação politécnica, dado de maneira isolada, fragmentada e não sistematizada.

Desta maneira, a educação politécnica, para Pistrak (2015), deveria se desenvolver em outro formato, quando

[...] As ciências naturais da escola devem desenvolver-se no campo geral do espírito prático, não dirigido ao utilitarismo do cotidiano, mas ampliado até a sua inclusão na luta de classes, em sistema de iniciativas que ajude nossa construção socialista em geral e o nosso desenvolvimento econômico e crescimento cultural particular. (Moscovita apud Pistrak, 2015, P. 121)

Em outras palavras, Pistrak (2015) justifica os recuos e ao mesmo tempo sublinha os avanços. Os avanços, na perspectiva do autor, foram à ligação do ensino ao trabalho produtivo e sublinha como limites a falta de encandeamento entre teoria e prática.

A centralidade do trabalho nos processos produtivos da União Soviética acarreta no sobrepujamento da técnica, passando a haver pouco envolvimento dos estudantes na luta de classes. Até 1921, as escolas soviéticas estavam preocupadas em formar o novo homem dentro das diversas instâncias organizativas, sublinhando que, mesmo na escola, os estudantes tinham espaços democráticos, fazendo com que as escolas fossem um pequeno soviete. De certa forma, o desmantelamento do sistema de sovietes, interfere diretamente na gestão organizacional das escolas, quando o caráter auto-gestionário é retirado do programa escolar, pois ao modificar os princípios basilares de uma educação revolucionária, perdem os elementos que poderiam ajudar na construção do homem novo.

O desenvolvimento das forças produtivas não se deu pela perspectiva do trabalho associado, antes, nas fábricas, manteve-se o estranhamento advindo das relações de exploração. O partido se confunde com o Estado e a educação politécnica torna-se uma educação pluriprofissional, havendo pouco espaço para o desenvolvimento integral do homem. Nesse sentido, o homem do futuro que estava sendo formado nos porões das fábricas, parece mais um cidadão burguês comum, que realizava um trabalho mecânico e repetitivo, havendo, inclusive, um desenvolvimento tímido das potencialidades artísticas.

Pistrak (2015), ao longo da discussão, critica duramente Gastev. Segundo o autor, Gastev era chamado de Taylor russo porque propunha métodos que superava a organização científica do trabalho, julgando o politecnismo como o domínio múltiplo de habilidades do trabalho, rejeitando todo e qualquer trabalho educativo, ignorando a agricultura, se sobrepondo as escolas monotécnicas com uma preparação pré-profissional bastante estreita.

Pistrak (2015) tinha consciência que, em termos gerais, o modelo de escolas politécnicas proposto por Gastev se distanciava de uma concepção mais progressista do que seja uma formação politécnica, pois, segundo a compreensão marxiana de politecnia, esta está assentada sob o princípio de desenvolver o intelecto e a formação física, atendendo a tríade educacional de mente, corpo e espírito. A formação para o trabalho, dentro da politecnia, refere-se a uma formação profissional mais ampliada, no qual atende a formação intelectual, o desenvolvimento físico e o próprio conhecimento técnico refere-se a todo o processo de formação. 
As demandas econômicas reivindicaram uma formação escolar afeita com todo o processo de industrialização. Dentro das metas, por exemplo, do plano quinquenal, está a mudança no modo de produção, no qual o trabalho seria o dono da produção, se constituindo, por conseguinte, numa expressão da industrialização e da reconstrução econômica dos próximos anos. Nesse sentido, a escola preparará para a produção com o trabalho dividido, tendo a tarefa, segundo Pistrak (2015), de preparar os membros da sociedade para que eles sejam desenvolvidos em todos os aspectos.

É verdade que, independente do sistema socioeconômico em voga, a escola servirá aos objetivos daquela sociedade em construção e, enquanto persistirem os estranhamentos advindos das relações de produção, acontecerá o conflito da transição, por estar localizado entre o velho e o novo. Pistrak (2015) tinha consciência das contradições que havia no campo da produção, além de que, sabia que a introdução de certos tipos de trabalho na escola não significava que havia se concretizado as tarefas das escolas politécnicas. Mas, como construir uma consciência revolucionária se os agentes que possuíam a função de formar a consciência revolucionária haviam sido incorporadas ao modus operandis do partido? Como formar a consciência revolucionária se, nesse período, o trabalho estava sendo militarizado, o que aprofundava os estranhamentos, além de os sindicatos haviam sido estatizados? Como a produção poderia fazer parte da vida cotidiana com a alienação das relações dominantes?

Portanto, podemos deduzir que o afunilamento de uma formação politécnica ampliada passa pela redução da práxis político-pedagógica da formação escolar. Nesse sentido, politecnia, omnilateralidade e instrução profissional são conceitos antagônicos, considerando que o primeiro só pode ser desenvolvido plenamente se existirem condições materiais para que abarque as outras dimensões da formação humana, a omnilateralidade, quando já não existirem as barreiras causais que impedem o livre desenvolvimento humano e a instrução profissional plenamente realizável numa sociedade na qual a educação atende a própria demanda do sistema capitalista.

\section{Considerações finais}

$\mathrm{Na}$ tentativa de aproximar as elaborações marxistas para a educação no que concerne ao termo “educação politécnica”, cabe comparar a similaridade das elaborações de Marx e Engels para a educação, segundo a perspectiva de Sousa Junior (2009) e as elaborações de Pistrak e Shulgin.

Pistrak e Shulgin possuem mais similaridades do que diferenças, especialmente porque ambos partem do mesmo referencial teórico, no entanto, divergem em questões básicas que dizem respeito a aplicabilidade do método e a conceituação geral de politecnia que, no decorrer dos anos, a perspectiva de Pistrak tornou-se parecida a instrução profissional pelo fato de que houve pouco espaço para trabalhar as outras dimensões do ser humano, além de que houve a transformação da práxis política revolucionária para uma práxis política burocratizada.

Conforme podemos notar, a partir do momento em que houve uma centralização do processo formativo centrado no trabalho e o trabalho por si é insuficiente na formação do sujeito revolucionário.

Portanto, podemos dizer que a educação soviética atendeu a uma demanda do próprio contexto 
histórico imediato. No primeiro momento, quando a dimensão da práxis política revolucionária esteve presente de modo mais efetivo visava a responder a dimensão prática organizacional de uma sociedade em ebulição. Havia uma necessidade concreta de focar na alfabetização associada à necessidade de organização da classe. Posteriormente, a prioridade foi mudando, tornando-se mais pluriprofissional, voltado para atender a formação de quadros de especialistas para atuar nas fábricas.

Contudo, podemos perceber que nenhuma das formas educacionais desenvolvidas na União Soviética esteve coadunada ao fim da emancipação humana, mas sim pensada para atender a necessidade imediata e com isso, o vislumbre da emancipação humana ficou apenas nas consignas e campanhas do partido. Esteve presente a educação técnico-profissionalizante e nem tampouco a politecnia, como uma proposta que atua na transição do reino da necessidade para o reino da necessidade pôde ser efetivada.

Desta maneira, quanto mais à educação para a práxis política revolucionária se afasta da construção de um currículo escolar que contemple os três pilares para uma educação revolucionária: trabalho, ensino e práxis, mais ela passa a ser dado em tempos separados da formação e a formação teórica deslocada de uma prática política revolucionária, torna-se instrumental técnico e, portanto, deficitária, por não conseguir extrair o estranhamento das relações produtivas que resvala nas práticas escolares semelhantes às de uma escola comum burguesa.

\section{Referências Bibliográficas}

ANDRADE, Ricardo Adriano de. "Notas sobre a educação na obra de Lênin". Revista HISTEDBR Online, Campinas, número especial, p. 210-224, abr/2011. Disponível em: http://www.histedbr.fe.unicamp.br/revista/edicoes/41e/art15_41e.pdf. Acesso em: 30/03/2015.

BITTAR, Marisa; FERREIRA JR, Amarílio. “A educação na Rússia de Lênin”. Revista HISTEDBR Online, Campinas, número especial, p. 377-396, abr/2011. Disponível em:

http://www.histedbr.fae.unicamp.br/revista/edicoes/41e/doc01_41e 2.pdf. Acesso em: 09/04/2014.

DORE, Rosemary. "O debate sobre o conceito de escola do trabalho na Revolução Soviética". In:

MENEZES NETO, Antonio Julio (org). Socialismo e Educação. Belo Horizonte, Editora Fino Traço, 2013.

FREITAS, Luiz Carlos de. "A luta por uma Pedagogia do Meio: revisitando um conceito". In: PISTRAK, Moisey Mikhaylovich (org.). A escola-comuna. São Paulo: Expressão Popular, 2009.

LILGE, Frederic. "Lênin e a política de educação". In: Educação \& realidade. Porto Alegre. Vol. 13, n. 2 (jul./dez. 1988), p. 3-22.

MANACORDA, Mario Aliguiero. Marx e a pedagogia moderna. São Paulo, Editora Cortez, 2000.

NOSELLA, Paolo. "Trabalho e perspectivas de formaç̃o dos trabalhadores: para além da formação politécnica". I Encontro Internacional de Trabalho e Perspectivas de Formação dos Trabalhadores. Fortaleza, Universidade Federal do Ceará, 07 a 09 de setembro de 2006.

OYAMA, Edison Riuitiro. Lênin, Educaşão e Revolução na República dos Sovietes. Universidade Federal Fluminense, Faculdade de Educação, Niterói, Rio de Janeiro, 2010. (Tese de doutorado)

PISTRAK, Moisey M. A escola Comuna. São Paulo, Expressão Popular, 2009. (Tradução de Luiz Carlos de Freitas). . Ensaios sobre a escola politécnica. Editora Expressão Popular, São Paulo, 2015. 
SAVIANI, Dermeval. Trabalho e educação: fundamentos ontológicos e históricos. Trabalho encomendado pelo GT - Trabalho e educação. 29a. Reunião anual da ANPED, Caxambu 2006

Fundamentos da escola do trabalho. São Paulo, Expressão Popular, $3^{\circ}$ edição, 2011. (Tradução de Daniel Aarão Reis Filho).

SOUSA JUNIOR, Justino. Marx e a crítica da educação: da expansão liberal democrática à crise regressivo-destrutiva do Capital. Aparecida SP, Editora Idéias \& Letras, 2010.

Educação, trabalho e práxis: uma contribuição ao debate brasileiro

sobre a politecnia. In: MENEZES NETO, A. J., CUNHA, D. M. et. al. (Orgs.)

Trabalho, política e formação humana: Interlocuções com Marx e Gramsci. São Paulo:

Xamã, 2009, pp. 99-114.

SHULGIN, Viktor N. Rumo ao politecnismo. São Paulo, Expressão Popular, 2013.

VÁSQUEZ, Adolfo Sánchez. Filosofia da práxis. Rio de Janeiro, Editora Paz e Terra, 1997.

\section{Notas:}

1 Universidade Federal do Ceará. Pedagoga pela Universidade Estadual do Ceará, Mestre em Educação e Doutoranda pela Universidade Federal do Ceará. Orcid: https://orcid.org/0000-0002-6791-5032 Email: izianesilvestre@yahoo.com.br

Recebido em: 24/02/2019

Aprovado em: 24/07/2019 